\title{
Patients Loyalty Framework towards Healthcare Services in Malaysia
}

\author{
Kastury Gohain ${ }^{1,2}$, Seethaletchumy Thambiah ${ }^{1} \&$ Tan Chuie Hong ${ }^{1}$ \\ ${ }^{1}$ Faculty of management, Multimedia University, Cyberjaya, Malaysia \\ ${ }^{2}$ Faculty of Business management and Professional studies, Management and Science University, Malaysia \\ Correspondence: Kastury Gohain, Faculty of Management, Multimedia University, Cyberjaya, Malaysia. E-mail: \\ kastury.gohain@gmail.com
}

Received: June 4, 2018

doi:10.5539/ijbm.v13n9p148
Accepted: July 21, 2018

Online Published: August 1, 2018

URL: https://doi.org/10.5539/ijbm.v13n9p148

\begin{abstract}
The goal of this research is to determine the components that compel the healthcare stakeholders to become loyal towards the system. With extensive literature study of previously completed work, six crucial variables has been finalized. Hence, these variables will be justified to uphold loyal patients in healthcare. The findings highlighted the importance of loyalty in medical care. The factors leading to loyalty are identified and the relationship between the distinguished variable and loyalty is reconfirmed as prior documented studies.
\end{abstract}

Keywords: service quality, patient loyalty, healthcare and consumer

\section{Introduction}

A conscientious investigation of the numerous researches in the area of service quality and consumer loyalty in healthcare system services reported that there has been limited number of studies that tried to find the dimensions of service quality leading to patient's loyalty. Majority of the prior studies on service quality and consumer loyalty has primarily focused into industries like telecommunication, hospitality, banking, restaurants, insurance and education.

There is no distinct term to define loyal patient in healthcare settings. Hence largely the idea of loyalty is adjusted or taken from other areas like business, marketing, banking, insurance or any general service industry. But recently there is increasing need and conviction to know the patient loyalty traits in healthcare. Previous investigations on patient loyalty are towards healthcare with primary intention of profit earning, controlling expenditure and increasing customers. There is no full proof as that a satisfied patient may still stick to the service provider. Whereas, situation where switching cost is very high, patient might not opt to change the medical care in spite of unsatisfactory services. Hence, it is imperative to explore the consequences of satisfaction and dissatisfaction with new measuring methods which can indisputably adapt to varied healthcare settings. The theory of loyal consumer is believed to be the presence of relation with an individual's belief for a body like image, service, outlet and dealer with one's committed behavior (Dick \& Basu, 1994). Therefore, this research will be an initiative to derive the attributes of loyal patient from the quality of service patient experience in a healthcare setting. The uniqueness of healthcare service is that different hospitals or centers caters with similar services, nevertheless way of delivery is dissimilar from hospital to hospital (Youssef, 1996).

\section{Development of Theoretical Framework}

The service quality assessment is undisputedly dominated by SERVQUAL scale to measure customer satisfaction which is based on expectation and perception gap analysis (Butt \& de Run, 2009). However, this is a generic evaluation process and holds ground for reformation to fit into the specific industry. Further, SERVQUAL measurement has been mostly used for developed societies, putting a drawback as it lacks investigation in developing countries across various settings of healthcare (Ramez, 2012).Initial work from Gronroos service quality model is known as perceived service quality model. This model concentrates into two aspects of service, the technical and functional service quality. Further, development of this model has led to the inclusion of the firm's image leading to satisfaction of customers. Subsequently, SERVQUAL scale comprises of ten dimensions to measure the consumers perceptions on the quality of service received. Additionally, two models's known as the RATER and GAP model were derived directly from the SERVQUAL theory. Reliability, assurance, tangibility, empathy and responsiveness are the five attributes of RATER model which describes more about the functional qualities in service delivery. The GAP model works as to fill the gap between the 
consumer's expectation and perception which might lead to bad service experiences. GAP model too finds the differences around the five dimensions of service as well. Eventually, the dimensions of word of mouth, personal needs and past experiences are stressed to shows its weight on customers expected feelings of service quality in the GAP model. The five qualities model of Zineldin (2006) applied on healthcare to measure patient perception of the services delivered is observed to be precise and have comprehensive attributes. These factors umbrella the aspects from the technical and functional qualities. The five dimensions got credence as the qualities of object (technical), process, interaction, atmosphere and infrastructure are uniquely developed to measure the patients opinion about the service quality in a healthcare organization. The list of dimensions for service qualities is in exhaustive. Numerous scholars have introduced, tested and justified different sets of quality dimensions to tap accurately the consumer's feelings for the service experience they witness. One of the components which have been entirely ignored in the healthcare institutions is the dimensions of social responsibility. Healthcare organizations are based on the constituent right of the citizens unlike other business enterprises. Social responsibility component in healthcare organization is more critical and challenging as they are solely established for the welfare of the citizens (On \& Ilieş, 2012). Additionally, social responsibility should include external environment, concerned about the outcomes and quality, the service process and creation of safety measures for staff and the users themselves. Thus, this reseacrh proposes the dimensions of social responsibility as as service quality factor.One of the important grounds for interest in service quality by managers and researchers follows from the perspective that it has positive effect in deciding the performance of the firm (Caruana, 2002). Van (2012) have addressed that loyalty is the forthright consequence of excellent contribution of service quality. Loyalty is believed to be an emotional relationship between the consumers and the providers. The quality of services received directly influences the user's decision behavior (Kulsum, Yanuar, \& Syah, 2017) .A congruous beneficial bond, a positive clinical outcome, and satisfaction can prevent patients from giving up the recognition in need or offered (Astuti \& Nagase, 2016). Thus, loyalty is evaluated by the users relationship strength (Nogami, 2016).Continuous use of product or service shows firm belief in the system which translates into loyalty. Loyalty is reflected in the customer's attitude and behavior. Where attitude helps to form trust and relationship and behavior shows the willingness to repeat use of the company's product or service. Therefore drawing links between the valuable aspects of service quality and its outcome in healthcare organization brings forward the loyalty framework for healthcare.

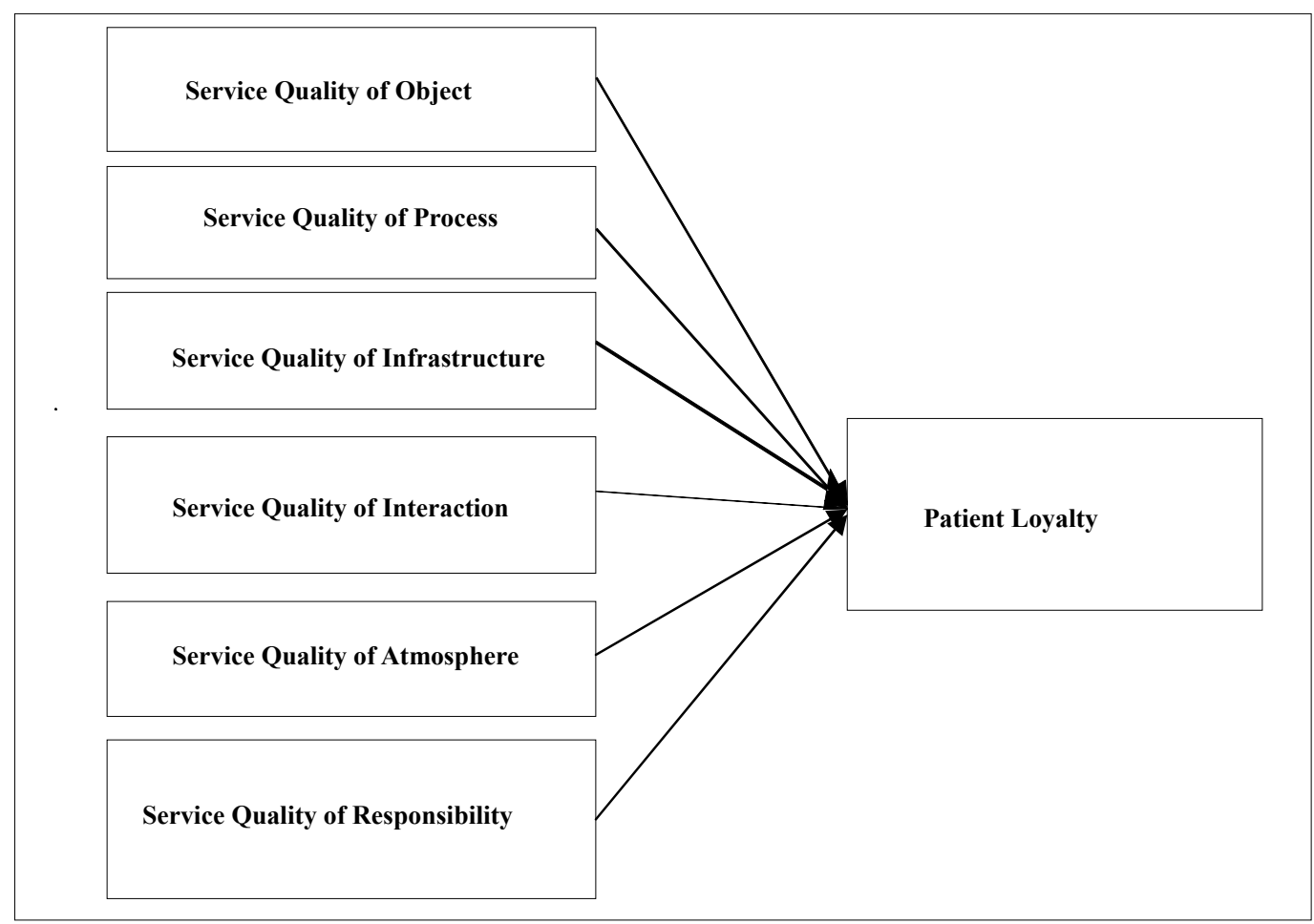

Figure 1. Loyalty framework for healthcare 


\section{Hypothesis Development}

\subsection{Service Quality of Object}

This quality of object valuates the medical treatment itself; the primary reason of a patient to visit a hospital (Zineldin, 2006).Patient decide a healthcare professional or a treatment on the criteria of whether the objective of getting good health is achieved (Zlotnik, 2013).

H1: There is a positive relationship between 'service quality of object' and patient's loyalty.

\subsection{Service Quality of Process}

This service quality evaluates how well healthcare activities are being executed and performed such as wait time and promptness in treating the patients. These activities are carried out by front-line nurses/physicians/pharmacist/lab technician and so on, at their facilities and helps in taking decision in treating patients.

$\mathrm{H} 2$ : There is a positive relationship between 'service quality of processes' and patient's loyalty.

\subsection{Service Quality of Infrastructure}

Infrastructure explains about the appropriate skills and attitudes which work as catalyst in utilizing the human and material resources in a hospital for the patients. Therefore, it needs to be addressed and as such the hypothesis derived to be as follows.

H3: There is a positive relationship between 'service quality of infrastructure' and patient's loyalty.

\subsection{Service Quality of Interaction}

Moira A. Stewart (1995) discovered that effective communication which is an interactive process exerts a positive influence not only on the emotional health of the patient but also in other symptom resolution. Chances are high that the amount of benefits received from relationship would be related highly to both satisfaction with those who benefits and are satisfied with the overall relationship with excellent interaction (Morgan \& Hunt, 1994).

H4: There is a positive relationship between 'service quality of interaction' and patient's loyalty.

\subsection{Service Quality of Atmosphere}

The service delivery performance between the providers and receivers can be impacted by the quality of atmosphere in a particular environment where they cooperate and conduct the activities (Zineldin, 2006). Good atmosphere is considered to be crucial to healthcare as it is about meeting the physical, psychological and social needs of people who seek care (James \& Bugembe, 2009).

H5: There is a positive relationship between 'service quality of atmosphere' and the patient's loyalty.

\subsection{Service Quality of Social Responsibility}

An organization's responsiveness to community requirements, thus social responsibility is considered to be accountable to act to external social duties keeping up to its quality of assumed ethical action, responsibility presupposes voluntary action taken to achieve the objectives that are socially accepted (Frunză, 2011).

H6: There is a positive relationship between 'service quality of social responsibility' and the patient's loyalty.

\section{Research Methodology}

A cross-sectional survey method will be conducted in this study to collect the primary data, whereby the real data will be collected from the outpatients in the healthcare centers (sample) only once. Non probability sampling technique will be applied to select the targeted patients from hospitals in Malaysia. The reason for choosing convenience sampling is because the list of patients, which is the sampling frame for this study, is confidential information and should not be disclosed. The condition of inclusion of sample in this investigation is the local outpatients who have taken service from the health care centers in two major hospitals in the state of Selangor. Itemized forms will be developed based on prior similar studies. The perception of the patients will be measured on a scale ranging from 1-strongly disagrees to 5 -strongly agree. The questionnaire for this study will consist of five sections. Each section has questions regarding the variables under study. The questionnaire will start with the demographic information of the respondents. Direct response will be considered from adult patients over the age of 18 years in 2017. G power analysis method will be used to determine the appropriate sample size. To apply power analyses, the values of alpha, power and effect size should be identified. The conventional value of alpha is set as 0.05 with proposed power value to be 0.08 (Green, 1991) accepted for a wide range of behavioral research. The targeted sample size to be at least 385 assuming the study has a $100 \%$ response rate. In order to get 
385 useable responses this study aims to distribute about 500 questionnaire survey in order to get a modest 385 useable responses.

\subsection{Statistical Method}

Statistical package for social science (SPSS) version 23.0 will be applied to key in the data and to summarize the demographic information of the respondents. Further, regression analysis will be applied to test the relationship between the independent and dependent variable. Additionally model fit will be tested and confirmatory factor analysis will be performed to evaluate the hypothesized relationship among the independent variables (service quality dimensions) dependent variable (patient loyalty).

\section{Conclusion}

The primary objective of this study is to explore the dimensions of service quality of patient emerging towards loyal patient to hospital. The theoretical investigation revealed that the six service quality dimension: object, process, infrastructure, interaction, atmosphere and social responsibility can be very crucial in determining loyalty factors. There are various types of speculation to know the appropriate dimensions to understand the patient's situation in a healthcare setting. Despite extensive theoretical trial and concern from authorities there are no decisive factors to estimate patient's perception towards the providers. Thus, theoretical findings of this research stands by the concept that patients will be satisfied with medical care, effective management of processes, up dated technical facilities, concern for patient contribution, answerability to social problems with support from the healthcare takers by giving a helpful atmosphere to patients in every visit for all treatments will instill the service qualities for loyal patients.

\subsection{Recommendation}

Healthcare authorities should apply the six service quality attributes studied to enhance the satisfaction of patients and build the patients loyalty towards the provider. Findings suggest importance of patient loyalty should be from patient's perspective to sustain competition.

\subsection{Implication}

This study will benefit the public healthcare centers leaders to entice the challenges they face while providing the services with factual information for administration and operations. Results of this study reveal that demand for healthcare has compounded over the decade and forecasted to heighten. Therefore, the variables studied in this research are an attempt to perceive and examine the quality of service in public healthcare on patient's loyalty to public healthcare centers in Malaysia. Service researchers and healthcare leaders have frequently recycled functional and technical quality dimensions to mend the service shortcomings obtained by patients. Patient's evaluation of tangibility and intangibility quality of service experienced is being used to known the core service rendered for patient satisfaction. But the constructs of atmosphere, interaction and social responsibility studied scantly, enable to theoretically understand the role played by these factors in the explanation of patient satisfaction and patient loyalty in particular.

\subsection{Limitation}

The proposed framework needs further validation with real data to prove it empirically. Our study focused only on public healthcare centers in Malaysia. Thus it ponders only on the perspective of patients from public hospitals. Further, it looks into the services delivered to outdoor patients only. Therefore, the finding needs to be applied to the population in general with caution.

\section{Reference}

Astuti, H. J., \& Nagase, K. (2016). A framework for conceptualizing patient loyalty to healthcare organizations. Health Services Management Research, 29(3), 70-78. https://doi.org/10.1177/0951484816663562

Butt, M. M., \& de Run, E. C. (2009). Private healthcare quality: applying a SERVQUAL model. International Journal of Health Care Quality Assurance, 23(7), 658-673. https://doi.org/10.1108/09526861011071580

Caruana, A. (2002). Service loyalty. European Journal of Marketing, 36(7/8), 811-828. https://doi.org/10.1108/03090560210430818

Dick, A. S., \& Basu, K. (1994). Customer Loyalty: Toward an Integrated Conceptual Framework. Journal of the Academy of Marketing Science, 22(2), 99-113. https://doi.org/10.1177/0092070394222001

Es, R. A. J. van. (2012). The Relationship between Service Quality and Customer Loyalty, and its Influence on Business Model Design, (September), 1-85.

Frunză, S. (2011). On the need for a model of social responsibility and public action as an ethical base for 
adequate, ethical and efficient resource allocation in the public health system of Romania. Revista de Cercetare Si Interventie Sociala, 33(1), 178-196.

Green, S. B. (1991). How Many Subjects Does It Take To Do A Regression Analysis. Zlotnik, 2013)Multivariate Behavioral Research, 26(3), 499-510. https://doi.org/10.1207/s15327906mbr2603_7

James, F., \& Bugembe, L. (2009). A Study of patients ' perceptions of quality of care at the Department of Outpatients in the Eastern Cape District Hospital, (March).

Kulsum, U., Yanuar, T., \& Syah, R. (2017). The Effect of Service Quality on Loyalty with Mediation of Patient Satisfaction, 6(3), 41-50.

Moira A. S. (1995). Effective physician-patient communication and health outcomes: a review. CMAJ: Canadian Medical Association Journal(Journal De l'AssociationMedicaleCanadienne), 152(9), 1423-1433.

Morgan, R. M., \& Hunt, S. D. (1994). The Commitment Trust-Theory of Relationship Marketing. Journal of Marketing. https://doi.org/10.2307/1252308

Nogami, H. (2016). Examine The Relations Between Patient Satisfaction. Loyalty \& Trust, 1-6.

On, A., \& Ilieş, C. (2012). Social Responsibility in Public Services Organizations The case of Tîrgu-Mureş $\begin{array}{lllll}\text { Penitentiary. Procedia Economics and } & \text { Finance, }\end{array}$ https://doi.org/10.1016/S2212-5671(12)00226-2

Ramez, W. S. (2012). Patients' Perception of Health Care Quality, Satisfaction and Behavioral Intention: An Empirical Study in Bahrain. International Journal of Business and Social Science, 3(18), 131-141.

Youssef, F. N. (1996). Health care quality in NHS hospitals. International Journal of Health Care Quality Assurance, 9(1), 15-28. https://doi.org/10.1108/09526869610109125

Zineldin, M. (2006). The quality of health care and patient satisfaction: an exploratory investigation of the 5Qs model at some Egyptian and Jordanian medical clinics. International Journal of Health Care Quality Assurance Incorporating Leadership in Health Services, 19(1), 60-92. https://doi.org/10.1108/09526860610642609

Zlotnik, K. L. (2013). The impact of hospital charaterisics on patient satisfaction in Carlifornis hospitals.

\section{Copyrights}

Copyright for this article is retained by the author(s), with first publication rights granted to the journal.

This is an open-access article distributed under the terms and conditions of the Creative Commons Attribution license (http://creativecommons.org/licenses/by/4.0/). 